\title{
The meaning and process of pain acceptance. Perceptions of women living with arthritis and fibromyalgia
}

\author{
Diane L LaChapelle PhD, Susan Lavoie BA, Ainsley Boudreau BA
}

DL LaChapelle, S Lavoie, A Boudreau. The meaning and process of pain acceptance. Perceptions of women living with arthritis and fibromyalgia. Pain Res Manage 2008;13(3):201-210.

BACKGROUND: Within the past 10 years, cognitive-behavioural pain management models have moved beyond the traditional focus on coping strategies and perceived control over pain, to incorporate mindfulness- and acceptance-based approaches. Pain acceptance is the process of giving up the struggle with pain and learning to live life despite pain. Acceptance is associated with lower levels of pain, disability and psychological distress. Relatively little is known, however, about how patients arrive at a state of acceptance without the aid of therapy.

OBJECTIVES: To explore personal definitions of acceptance and the factors that facilitate or hinder acceptance.

METHODS: Eleven focus groups, involving a total of 45 women with arthritis and fibromyalgia, were conducted.

RESULTS: The qualitative analysis revealed that, while the women rejected the word 'acceptance', they did agree with the main components of existing research definitions. The women's responses revealed that acceptance was a process of realizations and acknowledgements, including realizing that the pain was not normal and help was needed, receiving a diagnosis, acknowledging that there was no cure and realizing that they needed to redefine 'normal'. Diagnosis, social support, educating self and others, and self-care were factors that promoted acceptance. Struggling to retain a prepain identity, negative impacts on relationships, others not accepting their pain and the unspoken message that the pain was 'all in their head' were barriers to acceptance.

CONCLUSION: The implications of these findings, distinctions between the diagnostic groups and recommendations regarding how health professionals can facilitate the process of acceptance are discussed.

\section{Le processus d'acceptation de la douleur et sa signification : perceptions de femmes souffrant d'arthrite ou de fibromyalgie}

CONTEXTE : Au cours des 10 dernières années, les modèles cognitivocomportementaux de la prise en charge de la douleur ont dépassé les simples stratégies d'adaptation et de perception du soulagement de la douleur pour intégrer les approches fondées sur l'état d'esprit et l'acceptation. L'acceptation de la douleur est le processus qui consiste à abandonner la lutte contre la douleur et à apprendre à vivre avec celle-ci. L'acceptation est associée à des degrés moindres de douleur, d'incapacité et de détresse psychologique. Cependant, on connaît relativement peu de choses sur la façon dont les patients parviennent à un état d'acceptation sans le concours de la thérapeutique.

BUT : L'étude avait pour but d'examiner les définitions personnelles de l'acceptation ainsi que les facteurs qui facilitent ou entravent le processus. MÉTHODE : Onze groupes de discussion, totalisant 45 femmes souffrant d'arthrite ou de fibromyalgie, ont participé à l'étude.

RÉSULTATS : L'analyse qualitative a révélé que les femmes, tout en rejetant le terme " acceptation », étaient d'accord sur les principales composantes des définitions employées actuellement en recherche. Les réponses des femmes ont fait ressortir que l'acceptation était un processus de prise de conscience et de reconnaissance, notamment du fait que la douleur n'est pas un phénomène normal et qu'il faut de l'aide, du diagnostic, de la nature incurable de la maladie et de la nécessité de redéfinir la «normalité ». Le diagnostic, le soutien social, l'éducation des malades et celle des autres ainsi que les autosoins se sont montrés des facteurs d'acceptation. Par contre, le fait de vouloir conserver intacte son identité, les répercussions négatives sur les relations, la non-acceptation des autres et le message implicite que " c'est un mal imaginaire » se sont révélés des obstacles à l'acceptation.

CONCLUSION : La portée des résultats, les différences entre les groupes de diagnostic et les recommandations sur la façon dont les professionnels de la santé peuvent faciliter le processus d'acceptation sont débattues.

Key Words: Arthritis; Fibromyalgia; Pain acceptance

$\mathrm{T}$ he experience of persistent pain prompts a search for understanding that initially focuses on diagnosis and treatment recommendations that will eliminate the pain. When initial attempts are unsuccessful, patients often undertake a vigorous quest to find a cure (1). This search can dominate a person's life, leading him or her to try a variety of pharmacological, physical and 'alternative' therapies (2). When the pain experience continues, however, he or she is confronted with the reality of 'learning to live with' chronic pain $(1,3,4)$.

Consistent with this reality, researchers and clinicians in the cognitive-behavioural tradition have begun to embrace mindfulness- and acceptance-based approaches. Based on the 
initial work of Hayes et al $(5,6)$, Geiser (7) and McCracken et al $(1,8-10)$ extended the acceptance-based approach to persons with chronic pain. In this context, acceptance is generally viewed as "a willingness to experience continuing pain without needing to reduce, avoid, or otherwise change it" (8). Factor analysis of the main tool for measuring acceptance - the Chronic Pain Acceptance Questionnaire (CPAQ) - reveals four components: "(1) activity engagement (pursuit of life activities regardless of pain); (2) pain willingness (recognition that avoidance and control are often unworkable methods of adapting to chronic pain); (3) thought control (belief that pain can be controlled or changed by altering one's thoughts); and (4) chronicity (recognizing that pain may not change)" (9). Based on evaluation of the psychometric properties of these four subscales, however, McCracken et al (9) reduced the CPAQ to only two subscales (activity engagement and pain willingness).

Acceptance has emerged as a valuable construct in understanding adjustment. Using correlational designs, researchers demonstrated that acceptance is associated with better physical, social and emotional functioning $(1,11,12)$. Furthermore, in clinical studies $(1,7,10,13,14)$, researchers demonstrated that increased acceptance is associated with improvements in physical, social and emotional functioning, in work-related functioning, and in analgesic and health care use.

Despite the demonstrated benefits of acceptance, relatively little is known about how patients typically arrive at a state of acceptance when they do not undergo a formal acceptanceand commitment-based therapy (ACT) program. Although several studies have examined the general process of adjustment (15-17) and researchers are delineating how ACT can promote acceptance $(5,6)$, no study, to our knowledge, has investigated the meaning or process of pain acceptance outside of therapy. In a related study, Risdon et al (18) identified eight accounts of the meaning of acceptance among 30 individuals from the community (the mean age of participants was 46 years and the majority were women, but no further descriptive data regarding the sample characteristics were provided). The eight accounts identified were taking control, living dayto-day, acknowledging limitations, empowerment, accepting loss of self, acknowledging that there is more to life than pain, relinquishing the fight against battles that cannot be won and reliance on spiritual strength. However, only five of these participants identified themselves as having chronic pain. The intent of the present study was to examine the meaning and process of pain acceptance for individuals who have not participated in an ACT program. It is important to investigate the process of acceptance outside of therapy because the vast majority of persons with chronic pain never participate in formalized psychotherapy.

\section{Ethical approval}

\section{METHODS}

Ethical approval was received from the University of New Brunswick's Department of Psychology's Ethical Review Committee and the University's Research Ethics Board (Fredericton, New Brunswick).

\section{Participants}

At the outset of the present study, male and female participants were recruited. However, at the halfway point in the study, only two men had volunteered. For this reason, the study was restricted to women and the data from the two men were removed from the analysis. Participants included 45 women with arthritis or fibromyalgia (FM) who had not undergone any type of ACT program. The mean ( \pm SD) age of the participants was $51.4 \pm 12.2$ years (range 23 to 75 years). A majority of the women were married or common-law (64.5\%), and had university, college or postgraduate levels of education (64.4\%). Twenty per cent were unemployed, $31.1 \%$ were retired and $37.8 \%$ were working full- or part-time. Twenty individuals had FM, 13 had arthritis (including osteoarthritis, rheumatoid arthritis, systemic lupus erythematosus, ankylosing spondylitis and psoriatic arthritis), and 15 had both FM and another form of arthritis. On average, participants had been experiencing pain-related symptoms for $15 \pm 10.3$ years (range 0.5 to 39 years). The average length of time since diagnosis was $11 \pm 8.8$ years (range 0.5 to 37.5 years).

\section{Measures}

Before the focus group, participants completed a demographic and diagnostic questionnaire, and section 1 of the Multidimensional Pain Inventory (MPI) (19). The MPI assesses pain severity, pain interference with participation in daily life, perceived control over the pain, affective distress and social support. These subscales have demonstrated reliability and validity with heterogeneous samples of persons with pain (20). In the present sample, the internal consistency coefficients were: pain severity $\alpha=0.74$; pain interference $\alpha=0.92$; perceived control $\alpha=0.85$; perceived social support $\alpha=0.80$; and affective distress $\alpha=0.82$.

\section{Procedure}

Participants were recruited through community advertising, including posters in local organizations (eg, the local Arthritis Society), hospitals and doctors' offices, and announcements in local electronic newsletters. Inclusion criteria were age greater than 18 years, having received a diagnosis of arthritis or FM from a physician and being able to converse comfortably in English. Inclusion criteria were determined during telephone or electronic mail recruitment.

Eleven focus groups consisting of two to seven participants were conducted. Focus groups enable the exploration of issues among a group of people with common experiences (21), and are valuable in capturing the complexity of adaptation to chronic pain by allowing participants to describe their experiences in their own words in an environment that encourages self-exploration $(22,23)$. Given differences in the diagnosis and treatment of FM, and continued controversy surrounding FM $(24,25)$ compared with other types of arthritis, separate focus groups were conducted for this diagnostic group. Women who had both FM and another type of arthritis were included in the FM focus groups.

Each focus group began with informed consent procedures followed by completion of the questionnaires. The focus group discussions lasted between $1.5 \mathrm{~h}$ and $2 \mathrm{~h}$. Each group was facilitated by the primary researcher (Diane L LaChapelle) and another researcher. The focus groups were audiotaped and the cofacilitator took field notes.

There were three broad research questions: "What is acceptance from the perspective of persons living with pain?", "What 
facilitates acceptance?" and "What hinders acceptance?" The research topic was introduced with these comments:

Research has shown that it is helpful for people who have chronic pain to accept that they must learn to live with their pain rather than continuing to try and find a medication or treatment that will eliminate $100 \%$ of their pain. It is thought that the process of acceptance allows people to redirect their energy from finding a cure, toward finding ways of living a fulfilling and satisfying life despite the pain.

The key questions that guided the subsequent discussion were:

We would like to begin the discussion by asking each of you to share with us your own definitions of acceptance. For example, when someone says that they have been able to accept their arthritis or fibromyalgia and accept their pain, what does this mean to you?

Now we would be really interested in hearing about your own experiences in trying to accept your pain. What has helped you to accept or, if you still struggle to accept, what makes it hard?

The participants were prompted for further detail, additional examples or clarification, as necessary.

\section{Data analysis}

Each audiotape was transcribed verbatim and reviewed for accuracy by a second research assistant. Field notes were used to supplement the audio recording in one tape with some inaudible sections. The transcripts were imported into the qualitative computer program QSR NUD*IST NVIVO (QSR International Pty Ltd, USA) (26). The six phases of thematic analysis identified by Braun and Clarke (27) were used as a guideline during the analysis of the transcripts. The key questions from the semistructured interview guide were used to organize the main themes in a deductive fashion (27). The responses under each theme were then further analyzed to find subthemes via an inductive approach (27). Comparisons were conducted between individual responses within and across the focus groups. The themes were independently validated from the transcripts by two of the authors. Pseudonyms are used to protect anonymity and confidentiality.

\section{Pain experiences}

\section{RESULTS}

Participants reported moderate levels of pain severity (mean [ \pm SD] scale score and corresponding mean $\mathrm{T}$ scores $M=3.47 \pm 1.09 ; T=43.8 \pm 8.7)$, pain interference $(M=3.93 \pm 1.18$; $\mathrm{T}=48.9 \pm 8.0)$, perceived control over their pain $(\mathrm{M}=3.69 \pm 1.51$; $\mathrm{T}=55.0 \pm 11.2)$, negative $\operatorname{mood}(\mathrm{M}=3.07 \pm 1.31 ; \mathrm{T}=47.3 \pm 9.7)$ and perceived social support $(M=4.11 \pm 1.34 ; \mathrm{T}=48.2 \pm 8.7)$. Although the present sample had slightly lower levels of affective distress and higher levels of pain interference, the levels of these and the other subscales were generally quite comparable with those reported in the literature for a heterogeneous chronic pain sample, patients with fibromyalgia and lupus, and a community sample of women with back pain (28). Furthermore, the present sample had levels of adjustment that were better than a pretreatment sample of women with FM but lower than the post-treatment group (29).

\section{The meaning of acceptance}

In relation to the first research question, a comprehensive, concrete definition of acceptance was not within reach for the majority of the women. In fact, use of the word 'acceptance' proved to be a major obstacle. For the majority of the women, the word acceptance meant giving up or giving in to their pain. The women's frustration with the word is illustrated in Molly's (FM) comment: "I think acceptance is a rotten word." Instead, they preferred expressions such as 'embracing', 'dealing' or 'coming to terms' with their pain:

Maybe acceptance isn't a good word, I think of it not as accepting it but just dealing with it. (JoAnne, arthritis)

I question the word acceptance and I'm trying to see if my concept is actually different and I don't know [...] I still don't accept it but I embrace it in the sense that it's okay [...] I don't know if I still have trouble with the word 'accept', I don't know if 'embrace' is any better. I guess acceptance is coming to terms with, it's not just accepting the pain, but accepting the whole situation of which pain is part. (Nancy, arthritis)

I don't think I accept it. I'm just kinda living with it. You just kind of give up and say, well, it's here so I've got to go on. I can't just not live my life [...] Not accepting it's not letting it overtake your life - finding the courage to overcome the pain and to keep going. (Lydia, arthritis)

I'm not sure it's acceptance so much as defiance. I think that you spend a lot of time saying 'damn it, I'm going to do it'. You're not gonna stop. (Barbara, FM)

Despite dissatisfaction with the word 'acceptance', the women ultimately described 'embracing', 'dealing with' or 'coming to terms with' their pain in a manner that aligns quite closely with the two main components of acceptance identified by McCracken et al (9). The women's descriptions were most similar to the activity engagement component. That is, they commonly described acceptance as the "pursuit of life activities regardless of pain" (9). Barbara's (FM) ("you're not gonna stop") and Lydia's (arthritis) ("keep going") comments illustrated this, as did Madison's (arthritis and FM) when she stated, in agreement with another participant:

I understand what you said about shifting your energies, and that's exactly what happened when I finally did accept the fact that, okay, I wasn't going to be able to work and that I was going to have to do things differently $[. .$.$] that's where I shifted my energies [...] to the$ stuff that gives me pleasure.

The women's discussions also reflected the general concept of pain willingness (9). For instance, they often noted that they willingly engaged in activities that would cause pain rather than avoid the activity and lose out on an opportunity for joy:

I'll always be in the garden, I'll walk like an 80-year-old because my lower back is killing me, it's so stiff, but I do it anyways because that's kinda how I came to terms with it, I'm not going to stop living. (Yasmin, FM)

I have a nine-month-old grandchild and I don't care if it kills me, I'm gonna pick her up and carry her and I know I'm gonna suffer. (Bailey, FM) 
In addition, while they spoke frequently of the need for control, they spoke of controlling their lives but not of controlling the pain per se:

Coming to that acceptance [that there would be pain to deal with everyday] has pushed me to take more control of my life [...] I am the driver of the bus. (Karla, arthritis)

Acceptance is really about knowing what your limits are and knowing what you can do [...] and just trying to find a way to live a better life than you did and not try to find answers. (Carrie, FM)

Nancy (arthritis) said it eloquently when she summarized her thoughts on acceptance: "How can I work with the pain so that I can still have a quality of life".

It should be noted, however, that for these women, acceptance did not include "a willingness to experience continuing pain without needing to reduce, avoid, or otherwise change it" (8). That is, the women did not believe that hope for improvements in their pain (potentially through improved treatment options) was incompatible with acceptance. Madison's (FM and arthritis) comment below was typical among the women:

I don't think that accepting means giving up, and I think that we can always keep that little bit of hope. I mean, there's still maybe better medication that might come out, and it doesn't necessarily mean that it will or it will happen in our lifetime, but it might happen.

Consistent with the conclusion of McCracken et al (9) that thought control is not a key component of acceptance, we also did not find any references in the women's discussions related to this idea. A few women spoke of the benefit of keeping a positive outlook, but no one spoke specifically about a relationship between thoughts and pain experiences. In contrast, while McCracken et al (9) found that the chronicity component of the CPAQ was unrelated to patient functioning, chronicity was a very common theme in the women's discussions. Specifically, the realization that there was no cure, that the pain was indeed chronic, seemed to be an important turning point in the process of acceptance. Trudy (FM), for example, found that acceptance did not begin until "I stopped doing the research [for a cure] [...] It wasn't until I said 'okay, nothin's gonna fix it' [...] I stopped looking for the miracle." Similarly, Rhonda (FM) indicated "I know that I have it, I know that it's not going to go away, and I know there's no cure for it, so I try to deal with it as well as I can." Eve (arthritis and FM) stated "there is no cure, and acceptance means you've gotta get on with your life and cope."

At the end of one of the focus groups, Fay (FM) summarized her conceptualization of acceptance this way:

Acceptance to me is a stepping stone. If I hadn't got to that point, and I'm not saying it happened just like that, ah, for me personally, my life couldn't possibly be as fulfilling as it is, and I say fulfilling, knowing that it's not, it's not perfect or what I would have wanted, but I just knew from other things that have happened to me, I had to get on that stepping stone of acceptance, and it wasn't bowing down to it - it was kind of a freedom for me. It was like a weight off my back.

\section{The process of acceptance}

A consistent finding that emerged in all focus group discussions was the concept of acceptance as a process. It was evident that coming to terms with chronic pain takes time and repeated moments of insight. Across the 11 focus groups, the women described moving through a sequential series of realizations or acknowledgements that began in the early stages of the pain experience. The first two of these processes (I and II) represent precursors to acceptance, while the final process (VI) characterizes the ongoing maintenance of acceptance. Stages III to $\mathrm{V}$ embody the tasks typically facilitated in the psychotherapeutic context.

I. Realizing the need for help: The first step in the process was an eventual realization that the amount of pain being experienced was not normal. Once the need for help was acknowledged, medical care was sought to determine the cause of the pain and to receive treatment so they could return to their normal quality of life. This step represents initiation of a 'quest for the cure'.

II. Receiving a diagnosis: For a majority of the women, the most noteworthy turning point in the acceptance process was receiving a diagnosis. The diagnosis legitimized their struggle and provided a place to start in relation to understanding their condition and beginning to learn self-management strategies. Although receipt of a diagnosis was monumental for women in both diagnostic groups, it was vital to those with FM. These women often waited years to receive a diagnosis (several women had waited 30 to 40 years), thus delaying initiation of the acceptance process. Our findings reflect those of Asbring and Närvänen (24), who have noted that receiving a diagnosis is fundamental in legitimizing women's struggles with chronic fatigue syndrome and FM.

I didn't wait long for a diagnosis for arthritis, I mean that's more visible isn't it, it's $x$-rays, they see calcification [...] but I think that I probably waited too long for a diagnosis of FM and worried about it far too much [...] I felt much better when I knew what was wrong and that it was something to, uh, live with and cope with and get along with and that it wasn't gonna kill me so that's fine. (Christy, arthritis and FM)

I think for us with FM, before you even get to acceptance that you have the condition, it's having a diagnosis. You go for 10, 20, maybe more years without having a proper diagnosis $[\ldots]$ So it seems to be all in your head and you, people around you, your doctor, think it's all in your head [...] So for me, the absolute crux of the matter is to actually get that diagnosis first and then you can start to accept it. (Darlene, FM)

Just getting a diagnosis gave me a direction to go in [...] as opposed to 'oh no, it's all in your mind'. (Heather, arthritis)

III. Realizing there is no cure: The women's initial feelings of relief from having a diagnosis faded as they learned more about their condition and began to realize that there was no cure. Although they had received some validation regarding the pain they were experiencing, they also had to acknowledge that their hopes of returning to a 'normal' life were not realistic. This step in the process was often quite prolonged; many of the women resisted believing the pain was not temporary and they spent a lot of time and energy searching for a way to eliminate the pain. The importance of acknowledging the chronicity of the pain is illustrated in the earlier comments of Trudy (FM), Rhonda (FM) and Eve (arthritis and FM). This 
realization appears fundamental to the process of acceptance, as highlighted by Loretta (FM):

My brothers kind of kick-started the whole acceptance thing. They are both doctors...I came home with a diagnosis and they said, 'there is no cure, deal with it.' They say, 'you either live with it or you sit at home and mope about it. There is no cure, get on with your life.' I'm like, 'okay, guess I'll move on then.'

Many of the women noted that they had to make this acknowledgement repeatedly. Each time new hope was offered (eg, in the form of new medications, physical therapy options or 'alternative' therapies), they had to return to this phase of the acceptance process. There was also a marked difference for those women for whom surgery was an option (eg, knee or hip replacement for osteoarthritis); these women actively resisted accepting their pain because they were offered the hope of significant relief. In this group, anger was frequently expressed regarding the time they had to wait for surgery and potential pain relief.

IV. Realizing it could be worse: In acknowledging that the pain was not temporary, the women had to decide what it meant for their lives and their futures. The realization that their condition was not terminal, though it was painful and difficult to live with, provided the women with the opportunity to reframe their perceptions. The ability to identify other people in their lives who were 'worse off' helped give them strength to figure out ways to deal with the pain.

[...] every time I walk in that hospital for physio or bloodwork, I see people 10 times more poorly than me. You know, there is nothing wrong with me by comparison so you're grateful, grateful for that, that you're as good as you are. (Christy, arthritis and FM)

Sometimes it, it helps, you, you meet somebody who has arthritis and they're so much worse than you are that you can't feel sorry for yourself [...] quite often you see how well they're getting on with their life [...] and you think 'well, you know, what am I whining about' you know, that helps. (Ashley, arthritis)

V. Redefining normal: Once the women realized that returning to their earlier, 'normal' and pain-free life was no longer realistic, but that life could be worse, they began seeing that they needed to redefine 'normal' for themselves. Consistent with the formal definition of acceptance (8), letting go of prepain self-expectations and shifting their focus to what they could accomplish now, despite the pain, was an important next step. This redefinition was often described as a grieving process involving the mourning of multiple losses including their prepain identity, employment, financial security, hopes and plans for the future, and, in some cases, marriages, families and other social relationships:

We've talked about acceptance. While I was going through it, and now that I see it, it's like a grieving process. That's exactly what it was for me. It's like a grieving process and you gotta let it go [...] I was not accepting it because I didn't want to lose my health, and you know, I was going through the whole process and I came to realize you're grieving and it's okay, it's normal. So just let, just go through the process. (Natasha, FM)
I was like 'oh, I want to find a job' and I was offered an extremely good job and I really wanted it and I had to see her [family practice nurse] the day after I was offered the job and we talked about it and after about 20 minutes I remember just sitting there and that's when it hit me - I couldn't take this job and I couldn't stop crying. [...] I still have times where, out of the blue, lots of tears and things like that, so whether it's part of a grieving process or whether it's just a part of the way the body releases the frustration. (Nancy, arthritis)

The women often described experiencing moments of insight during which they were faced with a choice to follow a path that led to self-pity, anger and depression, or a different path that led to maximizing their quality of life. Interestingly, this aspect of the pain acceptance process is consistent with a more general view of "acceptance of disability", which Li and Moore (30) equate with "acceptance of loss" and a "process of value changes".

VI: Acceptance as an ongoing daily process: Although redefining 'normal' marked the end of the distinctive phases of the process, it was evident that acceptance was not an all or nothing phenomenon; it was a continuous process and it occurred on multiple levels. It was easier to accept pain on a cognitive level than it was to accept pain on an emotional level. Moreover, setbacks in the path to acceptance occurred on days when severe pain led to physical and emotional exhaustion.

[discussing the issue of taking a path toward acceptance versus depression] I think you are making a choice every day actually, whether or not you are going to take that route [...] You can't be the perfect patient all the time no matter how good your intentions are. At least I can't. Yeah, there is a little backsliding - sort of like dieting. (Abby, FM)

It, it's a slow process to get to that acceptance. It is a slow process. I, from my, for me, it was probably anywhere between, to totally accept and just everything, was probably five to seven years before I totally said 'hey, you know, I have to [interruption] ya, I have to make some changes' [...] like you go through different phases at different times. (Zelma, arthritis)

You know, you can't sidestep a lot of this stuff. It's almost like the grief process. You go through every one of those stages [...] Every time you have a flare, you're gonna go through them all again [...] You know, and when you have a really bad day or a really bad week, guess what? [laughs] Back to stage one again. And back through again. (Barbara, FM)

\section{Facilitators and barriers to acceptance}

The second research question addressed what factors acted as facilitators or barriers to the process of acceptance. There were two key themes related to facilitators: self-management and education, and perceived social support. Three themes focused on barriers: lack of support and acceptance from others, unrelenting pain experiences, and mounting losses and fighting to be 'normal'.

Facilitators of acceptance:

Self-management and education: Receipt of a diagnosis marked a significant turning point in the women's acceptance process. 
Having a diagnosis made it possible for them to begin educating themselves about the condition and about pain management approaches.

Getting informed has a lot to do with your acceptance. Uh, before, before I became totally informed, um, I would try to do things and try to ignore it and it just kept getting worse and worse and worse, so, um, getting educated made a big difference [...] I just started reading everything I could read. I, I went to all the health sites on the Internet, I picked up pamphlets and so on. (June, arthritis)

I was just happy to have a name and a place to start getting information. (Edie, FM)

Beyond traditional medical approaches, the women most frequently discussed exercise, diet, adequate sleep, humour and maintaining social relationships as the strategies that were most helpful in coping with their condition. Improvements in managing the condition and regaining a sense of control over their lives seemed to be a necessary part of the acceptance process. The women's quests to become effective self-managers focused on identifying strategies that would enable them to persist with valued activities despite the pain.

The women with FM reported relying much more on themselves for education than did the women with arthritis. Women with arthritis reported having more access to information and guidance through their health care specialists or through associations such as the Arthritis Society. Women with FM, on the other hand, felt that their health care professionals were not knowledgeable about the condition and that there were no readily available formal sources of help. As a result, they needed to be self-reliant in finding information and in taking responsibility to educate their own health care professionals.

The biggest thing I would suggest is if there is a way to have the literature that has how different people cope with it [...] If you are on your own it is really hard to try to figure out [...] I know there is a lot for arthritis but there isn't near as much in the literature for coping strategies for FM. It's pretty straightforward once you understand it, but if you don't... (Reanne, FM)

Well, what I did was printed off all the stuff I could find and then took a copy to my doctor; she has got a whole file of stuff that I have brought her. Plus she is learning from her experience with me what can work for some people and what might not work for others. (Donna, arthritis and FM)

Perceived social support: Perceived social support from family, friends, employers, patient support groups and health care professionals was extremely important to pain acceptance. The women noted that different types of support were needed and were obtained from different sources. Family and friends provided tangible and emotional support, but it was limited by a perceived lack of understanding and concerns about overburdening support systems.

I think that it's really important for you to tell your family, especially the family that is living with you, um, especially a partner, what you're feeling when you're feeling it [...] [My husband] knows, he knows what to look for, he knows to hold me for a few minutes. (Lise, arthritis and FM)

I feel sometimes, I keep thinking to myself, I'm dragging him down, but he's so positive about it. He's always there, which of course helps me deal with it. (Megan, arthritis and FM)

Some of the women used support groups, which were described as safe havens where feelings could be shared with others with similar conditions. Support groups provided information, encouragement and an outlet for anger and frustration. On-line support groups (for the few women who used them) were valuable during the night, when the women felt particularly alone and vulnerable.

Finding a support group too, people who are in a similar situation, through the Internet, or I found a peripheral neuropathy group in town, and it helped to talk to someone who wasn't family, because they've all heard it before and someone who really understands. And when they say 'I understand' you know they do. And they can have some constructive suggestions. (Amanda, arthritis)

However, support groups were not always positive experiences. Some women found them to be discouraging or even to be organized by people aiming to take advantage.

The [group] I went to was they had two people there trying to get you to buy products. (Paige, arthritis and FM)

I went to one meeting and I had the impression that some of these people were just building their whole life around the disease. It had become the central preoccupation and I didn't want that so I never went back. (Yasmin, FM)

Finally, professional counselling was invaluable for women who were able to afford it or had access through the health care team. As illustrated in the following quote from Amanda (arthritis), this assistance seemed especially useful in helping the women work through mourning their losses and redefining what 'normal' was for them:

Having a psychologist or someone to talk to [...] to help you with the anger, to help you with the denial and all the other stages of grieving you go through. It is really, really important $[. .$.$] .$

\section{Barriers to acceptance:}

Lack of support and acceptance from others: Support was necessary to the process of acceptance, and both overt and implied acts of nonsupport from others were distressing. Although a lack of professional health care support and access to adequate health care resources were significant problems for women from both diagnostic groups, it was more problematic for those with FM. These women were often made to feel as if their pain was psychosomatic, as illustrated in the comment by Reanne (FM): "So I thought a lot of it's in my head. I am kind of crazy. I'm a sickly crazy person who looks reasonably healthy." This finding is quite consistent with the findings from other studies of women with FM (31), chronic muscular pain (32) and endometriosis (33). Moreover, without a diagnosis to legitimize their complaints, they could not offer concrete explanations to their family, friends or employers who often came to 
treat them in the same manner as the health care professional. The often long delay between symptom onset and diagnosis frequently led to irreparable damage to the women's social support networks.

Well, I accept it but it's the people around me that don't. (Rhonda, FM)

Kids resent it, you know - if their mothers can't do everything that the other mothers do or if, you know, their family is organized differently. Kids resent it. (Abby, FM)

It took years and years for me to accept that [that she must always go home early] and for him [husband] not to resent it. So other people have these expectations for you even though you know it's bad for you. (Dacey, FM)

Unrelenting pain experiences: Although the quality of the pain sensations changed over time, its unrelenting nature and presence was a barrier to acceptance because it drained the women's physical and emotional resources. Many indicated that fatigue was the most difficult aspect of their chronic illness to deal with.

As much as you want to accept it, and I know exactly what you're talkin' about right now because I could get a tear also, and I think everybody could here. It's hard on the head. It is really hard on the head because you have to deal with this every day. (Natasha, FM)

The biggest thing, I was tired. The fatigue was the worst - because you can't handle anything if you are that fatigued. The pain, anything, you can't handle it. (Reanne, FM)

Mounting losses and the fight to be 'normal': Perhaps the most significant barrier to the women's acceptance was the struggle to maintain their prepain identity. A prevalent attitude was that making lifestyle changes meant they had let the pain win. As a result, they often used their limited physical, mental and emotional energy to maintain an appearance of normalcy (eg, by continuing to work full-time, caring for their home and family, etc). Maintaining appearances was described as "putting on a play all day long" (Donna, arthritis and FM) or being "conditioned to cover it up" (Dacey, FM). The result was that their health status and quality of life further declined, often until they hit a crisis point that forced them to re-evaluate. This struggle was described by Nancy (arthritis) as "fighting the wrong way - when I fought to be normal, the pain was worse". Ultimately, acceptance of chronic pain was inescapably tied to acceptance of a changed identity. Acceptance required an ability to re-evaluate priorities and to focus on what was now possible given the reality of life with chronic pain.

I think guilt is another thing. Yes, because you're a partner in a marriage and you know, normally, you used to do all these things along with your partner and, all of a sudden, your partner is having to do more and more and more, and you're doing less and less and guilt sets in [...] And I think, that, at the beginning, hinders it [acceptance] but then after a while, you realize that that's wasted energy. (June, arthritis)

...and getting caught up in that too [other people's expectations] right, I mean I, I'm a responsible person, I want to do a good job, I don't want to go back to my job and not do it well. And, uh, so I put that on myself, obviously, but and so that gets in the way of me accepting that I have this and I have to change the way I do things in order to manage it. (Karla, arthritis)

\section{DISCUSSION}

\section{The meaning of pain acceptance}

The women in our focus groups objected to use of the word 'acceptance', instead preferring terms such as 'coping', 'coming to terms' or 'dealing' with the pain. Despite displeasure with the word, however, the women defined their personal acceptance in a manner that was consistent with three components of acceptance proposed by McCracken et al (9): activity engagement, pain willingness and chronicity. A willingness to acknowledge the chronicity of their condition appeared to be an important step toward achieving attitudes and behaviours that are consistent with activity engagement and pain willingness. However, the extent to which these two latter constructs are unique is unclear; they may be 'opposite sides of the same coin'. That is, once the women realized they were unwilling to give up their valued activities (ie, they were willing to pursue their values despite the pain), they naturally re-engaged in those activities. Overall, the women's rejection of the term 'acceptance' appears to reflect their belief that, to 'live with' their pain, they must learn to be effective self-managers of their pain. Furthermore, rejection of the term 'acceptance' reflects the women's beliefs that acceptance equates with resignation. Resignation, in turn, runs counter to their belief that they can maintain hope for improvement in their pain while, at the same time, being 'willing' to experience pain in the pursuit of valued activities. Because the meaning individuals ascribed to language is a strong precursor to their behaviour, practitioners may find it easier to build a rapport with patients if they use the language preferred by patients, particularly in the early stages of the chronic pain condition.

\section{The process of pain acceptance}

As McCracken (34) has noted, acceptance is not a decision or belief about pain but a process by which patients begin to make lifestyle choices that maximize their quality of life. Our study has added significantly to the literature on acceptance by delineating what is involved in the process of acceptance for individuals who have not had access to an ACT program. Based on the analysis of the focus group transcripts, it was evident that the process of acceptance could not begin to unfold without a diagnosis. Obtaining a diagnosis was a key turning point, and it often took a long time and much effort. Along the way, the women's suffering was minimized and they were discredited. This experience of delegitimization is similar to the experiences of women with endometriosis, chronic muscular pain, FM and chronic fatigue syndrome identified in previous studies (25,31-33). As Whelen (33) has noted, diagnosis is often considered by the women to represent a "validation of their embodied experience and credibility".

Once a diagnosis was received, the acceptance process seemed to halt as the women sought out a variety of treatments to eliminate or significantly reduce the pain. Although this pause in the acceptance process can be frustrating for practitioners, the search for a cure is an integral part of the process. The women clearly indicated that they could not move forward until they were sure all avenues of treatment had been 
adequately explored. It was also evident that the women needed to gain first-hand knowledge about the effectiveness of various treatment options; being told by their practitioner or another patient that something would not help was not sufficient.

Once the women were able to acknowledge there was no cure, acceptance - as more formally conceptualized by Hayes et al $(5,6)$ and McCracken et al $(1,8,9)$ - could begin by means of redefining what was 'normal'. This was another prolonged stage because it involved simultaneously mourning the loss of their 'old' life and establishing a 'new' life in the context of their new reality. Redefining 'normal' involved much of what the community sample in Risdon et al (18) described in their accounts of acceptance, including acknowledging limitations, empowerment, accepting loss of self, acknowledging there is more to life than pain and relinquishing the fight against battles that cannot be won. An important observation gleaned in the current study is that the process of acceptance is not linear; there is no beginning or end point, and it is not unidirectional. While patients generally will move toward greater acceptance over time, their level of acceptance will continue to fluctuate.

One question raised in the present study (as well as by Nicholas and Asghari [35]) is the extent to which the concept of acceptance overlaps with other constructs such as coping, adjustment, adaptation, self-efficacy and cognitive restructuring. According to Hayes (36), acceptance involves psychological flexibility, including being in the present moment and "based on what the situation affords, changing or persisting in behaviour in the service of chosen values". Consistent with this theory, our results suggest that acceptance represented an overall attitude toward the pain experience involving acknowledgement of the chronicity of the condition and a willingness to engage in valued activities despite pain. Furthermore, acceptance represented a necessary foundation for improved adjustment (ie, better social, physical and emotional functioning). The initial acceptance of chronicity initiated a process whereby the women began testing different ways of managing their condition. Furthermore, by a process of accommodation (changing cognitive schema "to accommodate the idea that some health problems cannot be fixed" and "adjusting one's self-concept...to accommodate chronic pain" [37]), the women redefined what was 'normal'. This involved re-evaluating priorities in relation to chosen values and re-engaging in those valued activities. As the women began to see themselves as effective self-managers, their confidence and self-efficacy grew, and this created a positive feedback loop with higher levels of acceptance.

Although the women had not participated in any formalized ACT program, there were many instances in which they described the process in a way that was consistent with what would be encouraged during therapy (eg, identifying core values and making a behavioural commitment to act in accordance with those values). In contrast, another central aspect of ACT (being in the moment/mindfulness) was not identified by the women as a key part of their acceptance process (this was mentioned by only two women within the same focus group). Thus, there are marked differences in the process by which acceptance is achieved within and outside of formal therapy. Given the accumulating evidence that ACT contributes to positive treatment gains among persons with pain (38), it can be surmised that ACT speeds up the process of acceptance. Given that many of the women in our groups indicated that acceptance had taken them five years or longer, shortening the length of time it takes to develop acceptance would improve outcomes.

Factors facilitating and impeding the process of acceptance As noted previously, patients need to be sure for themselves that everything has been done to identify and treat the source of their pain before they will engage in the process of 'learning to live' with the pain. As such, timely access to family physicians, specialists (eg, rheumatologists) and allied health professionals (nurses, physiotherapists, occupational therapists, psychologists) would help to promote the acceptance process by reducing the length of time patients struggle to find the cure. Throughout the process of 'coming to terms' with chronic pain, perceived social support was essential. Suggestions (regardless of their subtlety) that the women were malingering caused great distress and ultimately resulted in the women's energy being directed away from the acceptance process, and toward convincing others of the reality of their pain. This phenomenon of trying to convince others that the pain and suffering is real has also been observed in other patient populations (33). In moving toward redefining their personal identity, the women noted that formal support from a mental health professional was particularly valuable. Increased access to these resources would likely prove to be cost-effective by decreasing emotional distress, decreasing physician visits and promoting the adoption of effective selfmanagement strategies.

A second factor that significantly helped in the process of acceptance was to become knowledgeable about the pain condition and thereby learn how best to manage it. Unfortunately, most of the women (especially those with FM) felt they had been given little guidance about reputable sources of information. As a result, it likely took longer than necessary for the women to become experts in managing their own conditions. The result may be excessive use of health care resources. A simple and cost-effective solution would be for physicians to provide reading materials and to refer patients to reputable community organizations (eg, The Arthritis Society). Another cost-effective solution would be to increase access to nurse-practitioners or nurse-educators within the primary care setting who could provide valuable education about the pain condition and effective management strategies. Learning effective self-management strategies is essential in helping the women better cope with the unrelenting nature of chronic pain and to regain a sense of control over their lives.

\section{Limitations}

The use of qualitative focus group interviews enabled us to gain a better understanding of women's personal perspectives on the definition and process of acceptance. As noted by Busch (39), and Hallberg and Carlsson (23), this methodology is particularly valuable in tracing developmental changes and capturing the complexity of adaptation to chronic pain. Capturing this developmental process relied on the women's retrospective account of their struggle with pain acceptance. These accounts may have been coloured by the women's current experience of acceptance. Use of a focus group format also risks the possibility that the women's contributions were shaped to fit the norms within their group. However, the women frequently voiced differences of opinion among themselves on 
issues such as the meaning of acceptance, the value of alternative approaches to self-management, the ability of family and friends to understand or offer support, and the value of selfhelp groups and books. Finally, we cannot claim that these findings are generalizable to other women with chronic pain; a convenience sample of volunteers may differ from other types of patient samples. The similarity between the MPI scores of our participants and those reported in the literature, however, suggests that our sample was likely not significantly different from other patient groups. In addition, the validity of the findings are supported by their consistency with the quantitative work of McCracken et al (9) and with the qualitative work of Risdon et al (18) on acceptance. The validity and generalizability of the findings are further supported by the parallels observed between the experiences of the women in our study and how women with FM $(25,31)$, chronic fatigue (25) and endometriosis (33) have described their process of adjustment to chronic illness. These findings help advance our understanding of the acceptance process among the majority of patients who do not have access to formal psychotherapy programs. Additional research will be necessary to further test the validity of our findings in other populations of persons with pain (eg, neuropathic pain, low back pain) and among men with chronic pain.

\section{Directions for future research}

Acceptance appears to be a vital part of adjusting to chronic pain but, to maximize adjustment, effective self-management is also necessary. The relationship between acceptance and adjustment is likely bidirectional, with improvements in one facilitating further improvements in the other. A longitudinal study is needed to further understand this relationship. Also, given the emphasis our participants placed on needing to become knowledgeable self-managers of their conditions, research is needed to determine the optimal time to present patients with disease-related information (40). A balance must be achieved between presenting too much information such that patients become overwhelmed, and presenting too little information. Related to this, the value of ACT in helping persons with 'medically unexplained symptoms' (or as yet undiagnosed chronic illnesses) accept medical uncertainty should be explored. Finally, further research is needed to identify whether the current findings are relevant to men with chronic pain.

ACKNOWLEDGEMENTS: The assistance of Tanya Bollivar and William Johnston in transcribing the focus group interviews, and Tracy Hands in recruiting participants and organizing the focus groups is gratefully acknowledged. The authors also offer their gratitude and appreciation to the women who shared their experiences with them. They should be thought of as collaborators in our efforts to understand the lived experience of chronic pain.

FUNDING: Preparation of the present paper was supported, in part, by a University of New Brunswick New Faculty Research Grant.

DISCLOSURE: A portion of the present paper was presented at the annual conference of the Canadian Pain Society, Ottawa, Ontario, May 23 to 26, 2007.

\section{REFERENCES}

1. McCracken LM. Learning to live with the pain: Acceptance of pain predicts adjustment in persons with chronic pain. Pain 1998;74:21-7.

2. Candib LM. Making sense of my thumbs: Coming to terms with chronic illness. Families, Systems, \& Health 2004;22:139-51.

3. Crook J, Weir R, Tunks E. An epidemiological follow-up survey of persistent pain sufferers in a group family practice and speciality pain clinic. Pain 1989;36:49-61.

4. Turk DC. Customizing treatment for chronic pain patients: Who, what, and why? Pain 1990;6:255-70.

5. Hayes SC, Strosahl K, Wilson KG. Acceptance and Commitment Therapy: An Experimental Approach to Behavior Change. New York: Guilford Press, 1999.

6. Hayes SC, Strosahl K. Acceptance and commitment therapy. New York: Springer, 2004.

7. Geiser DS. A comparison of acceptance-focused and controlfocused interventions in a chronic pain treatment center. Digital Dissertations, 1992.

8. McCracken LM. Behavioral constituents of chronic pain acceptance: Results from factor analysis of the Chronic Pain Acceptance Questionnaire. J Back Musculoskeletal Rehabil 1999;13:93-100.

9. McCracken LM, Vowles KE, Eccleston C. Acceptance of chronic pain: Component analysis and a revised assessment method. Pain 2004;107:159-66.

10. McCracken LM, Vowles KE, Eccleston C. Acceptance-based treatment for persons with complex, long standing chronic pain: A preliminary analysis of treatment outcome in comparison to a waiting phase. Behav Res Ther 2005;43:1335-46.

11. McCracken LM, Eccleston C. Coping or acceptance: What to do about chronic pain? Pain 2003;105:197-204.

12. Viane I, Crombez G, Eccleston C, et al. Acceptance of pain is an independent predictor of mental well-being in patients with chronic pain: Empirical evidence and reappraisal. Pain 2003;106:65-72.

13. McCracken LM, Eccleston C, Bell C. Clinical assessment of behavioral coping responses: Preliminary results from a brief inventory. Eur J Pain 2005;9:69-78.

14. McCracken LM, Eccleston C. A comparison of the relative utility of coping and acceptance- based measures in a sample of chronic pain sufferers. Eur J Pain 2006;10:23-9.

15. Schaefer KM. Struggling to maintain a balance: A study of women living with fibromyalgia. J Adv Nurs 1995;21:95-102.

16. Walker J, Holloway I, Sofaer B. In the system: The lived experience of chronic back pain from the perspectives of those seeking help from pain clinics. Pain 1999;80:621-8.

17. Gullacksen AC, Lidbeck J. The life adjustment process in chronic pain: Psychosocial assessment and clinical implications. Pain Res Manage 2004;9:145-53.

18. Risdon A, Eccleston C, Crombez G, McCracken L. How can we learn to live with pain? A Q-methodological analysis of the diverse understandings of acceptance of chronic pain. Soc Sci Med 2003;56:375-86.

19. Kerns RD, Turk DC, Rudy TE. The West Haven-Yale Multidimensional Pain Inventory (WHYMPI). Pain 1985;23:345-56.

20. Bradley LA, McDonald-Haile J, Jaworski TM. Assessment of psychological status using interviews and self-report instruments. In: Turk DC, Melzack R, eds. The Handbook of Pain Assessment, 2nd edn. New York: Guilford Press, 2001.

21. Templeton, JF. The Focus Group: A Strategic Guide to Organizing, Conducting, and Analyzing the Focus Group Interview. Revised edition. Chicago: Probus, 1994.

22. Sim J. Collecting and analyzing qualitative data: Issues raised by the focus group. J Adv Nurs 1998;28;345-52.

23. Hallberg LR, Carlsson SG. Coping with fibromyalgia: A qualitative study. Scand J Caring Sci 2000;14:29-36.

24. Åsbring P, Närvänen A. Women's experiences of stigma in relation to chronic fatigue syndrome and fibromyalgia. Qual Health Res 2002;12:148-160.

25. Reich JW, Johnson LM, Zautra AJ, Davis MC. Uncertainty of illness relationships with mental health and coping processes in fibromyalgia patients. J Behav Med 2006;29:307-16.

26. QSR International. NVivo: NUD*IST for qualitative research. Melbourne: QSR International Pty Ltd, 2000. 
27. Braun V, Clark V. Using thematic analysis in psychology. Qual Res Psychol 2006;3:77-101.

28. Kerns RD, Turk DC, Rudy TE. Multidimensional Pain Inventory: Normative Data.

$<$ http://www.pain.pitt.edu/mpi/MPI_Norms.pdf $>$ (Version current at May 27, 2008).

29. Hooten WM, Townsend CO, Decker PA. Gender differences among patients with fibromyalgia undergoing multidisciplinary pain rehabilitation. Pain Med 2007;8:624-32.

30. Li L, Moore D. Acceptance of disability and its correlates. J Soc Psychol 1998;138:13-25.

31. Werner A, Isaksen LW, Malterud K. 'I am not the kind of woman who complains of everything': Illness stories on self and shame in women with chronic pain. Soc Sci Med 2004;59:1035-45.

32. Werner A, Malterud K. It is hard work behaving as a credible patient: Encounters between women with chronic pain and their doctors. Soc Sci Med 2003;57:1409-19.

33. Whelan E. 'No one agrees except for those of us who have it': Endometriosis patients as an epistemological community. Sociol Health Illn 2007;29:957-82.
34. McCracken LM. Social context and acceptance of chronic pain: The role of solicitous and punishing responses. Pain 2005;113:155-9.

35. Nicholas MK, Asghari A. Investigating acceptance in adjustment to chronic pain: Is acceptance broader than we thought? Pain 2006;124:269-79.

36. Hayes S. Acceptance \& Commitment Therapy (ACT). May 1, 2005. $<$ http://www.contextualpsychology.org/act> (Version current at May 27, 2008).

37. Jacob MC, Kerns RD, Rosenberg R, Haythornthwaite J. Chronic pain: Intrusion and accommodation. Behav Res Ther 1993;31:519-27.

38. McCracken LM. Contextual Cognitive-Behavioural Therapy for Chronic Pain. Progress in Pain Research and Management, Vol 33. Seattle: IASP Press, 2005.

39. Busch H. Appraisal and coping processes among chronic low back pain patients. Scand J Caring Sci 2005;19:346-402.

40. Barlow JH, Cullen LA, Rowe IF. Comparison of knowledge and psychological well-being between patients with a short disease duration $(<$ or $=1$ year $)$ and patients with more established rheumatoid arthritis ( $>$ or $=10$ years duration). Patient Educ Couns 1999;38:195-203. 


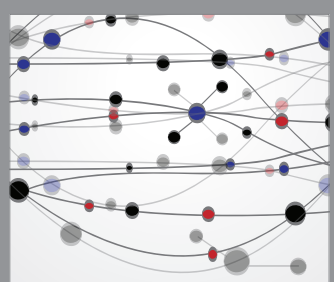

The Scientific World Journal
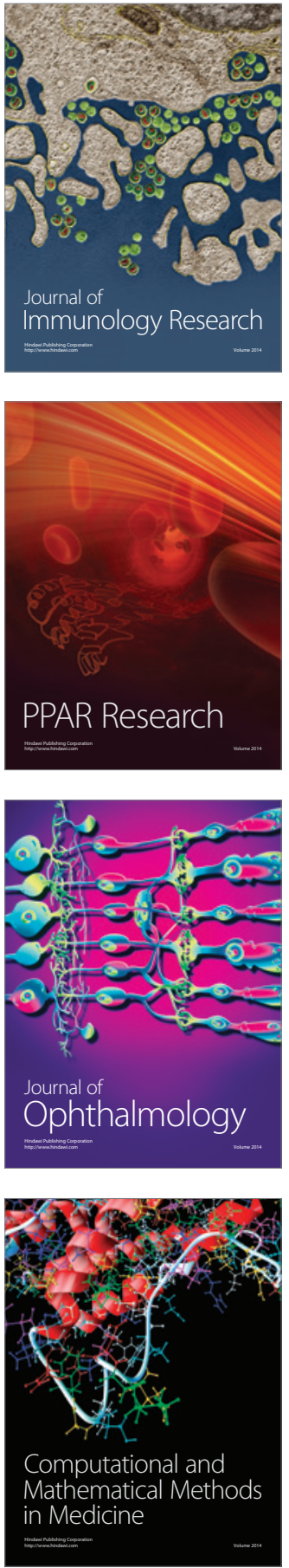

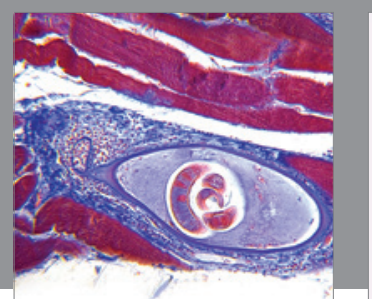

Gastroenterology Research and Practice

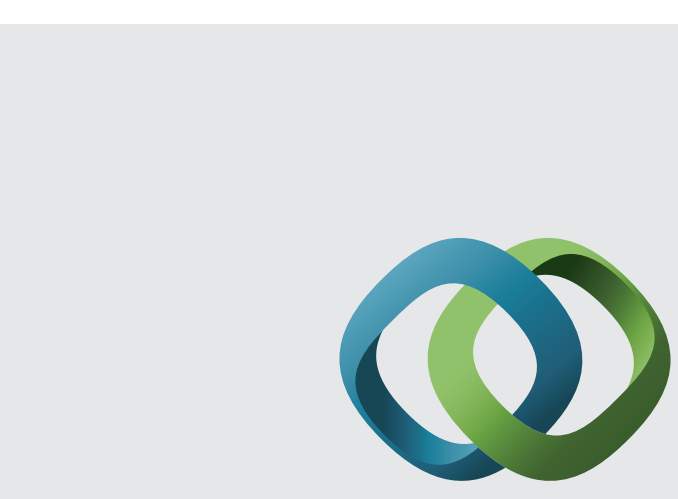

\section{Hindawi}

Submit your manuscripts at

http://www.hindawi.com
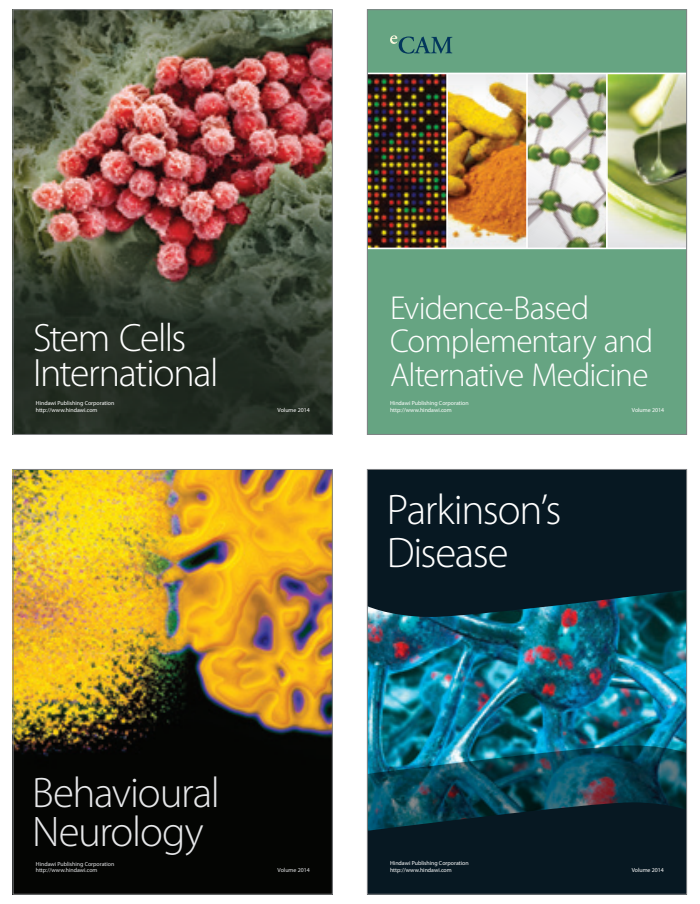
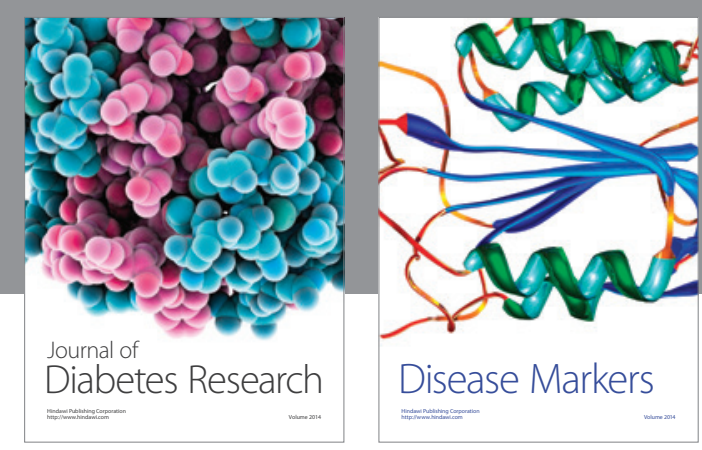

Disease Markers
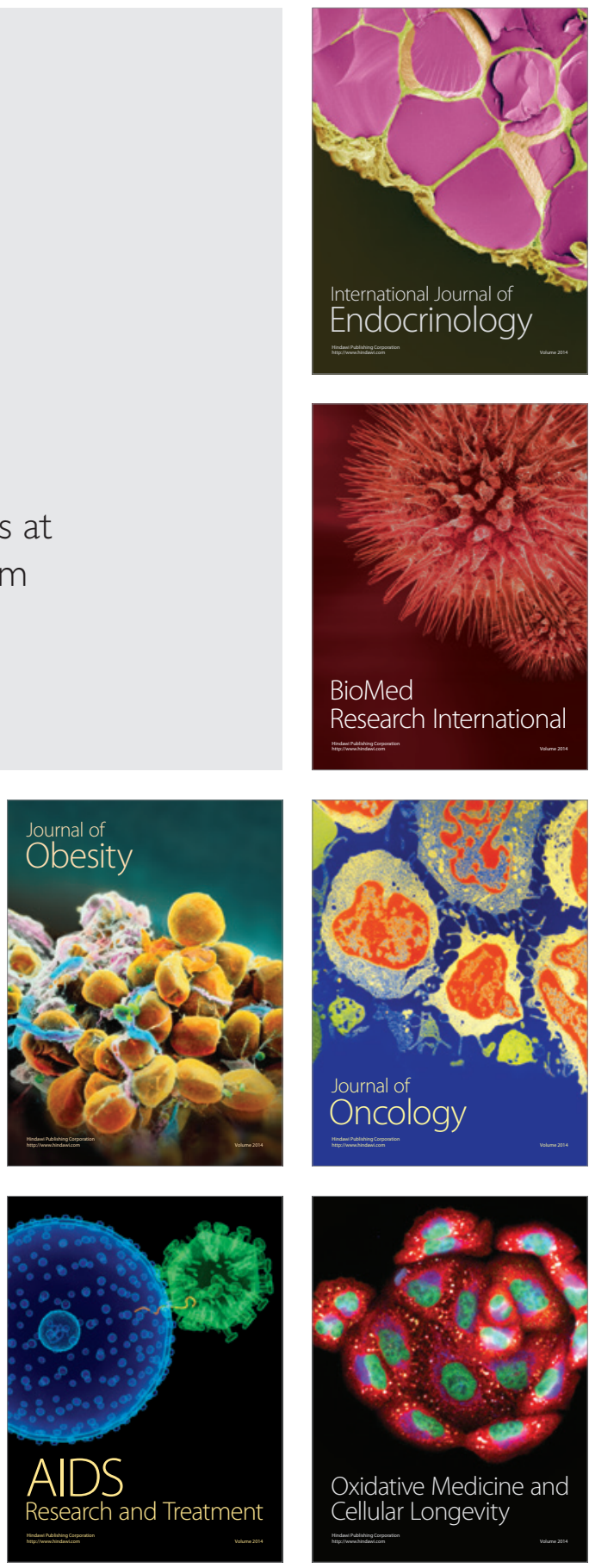